\title{
Toxicological Evaluation of Occidiofungin against Mice and Human Cancer Cell Lines
}

\author{
Steven Lai Hing1, Akshaya Ravichandran', Jerome Escano1, Jim Cooley², Frank Austin², \\ Shi-En Lu ${ }^{3}$, Stephen Pruett ${ }^{4}$, Leif Smith ${ }^{*}$ \\ ${ }^{1}$ Department of Biological Sciences, Texas A\&M University, College Station, USA \\ ${ }^{2}$ Department of Pathobiology and Population Medicine, College of Veterinary Medicine, Mississippi State \\ University, USA \\ ${ }^{3}$ Department of Biochemistry, Molecular Biology, Entomology and Plant Pathology, Mississippi State University, \\ USA \\ ${ }^{4}$ Department of Basic Sciences, College of Veterinary Medicine, Mississippi State University, USA \\ Email: ${ }^{*}$ jsmith@bio.tamu.edu
}

Received 8 September 2014; revised 6 October 2014; accepted 23 October 2014

Copyright (C) 2014 by authors and Scientific Research Publishing Inc.

This work is licensed under the Creative Commons Attribution International License (CC BY).

http://creativecommons.org/licenses/by/4.0/

(c) (i) Open Access

\section{Abstract}

Occidiofungin, a glyco-lipopeptide obtained from the liquid culture of Burkholderia contaminans MS14, has been identified as a novel fungicide. The natural product was shown to have a minimal amount of toxicity in a previous mouse toxicity study following intraperitoneal and subcutaneous administration. In this study, the toxicity of occidiofungin was evaluated following a $5 \mathrm{mg} / \mathrm{kg}$ intravenous tail vein injection. In addition, the toxicity of occidiofungin was evaluated against human fibroblast and cancer cell lines. Weight loss was the most significant observation following intravenous administration of occidiofungin. Histology, hematology, and blood serum chemistry did not reveal any significant signs of toxicity. The activity observed in the in vitro cytotoxicity assay against the cancer cell lines was all below $75 \mathrm{nM}$ concentration of occidiofungin. To date, the potency of occidiofungin against these cancer cell lines is greater than any activity observed against fungi. The findings in this study support the need to further evaluate occidiofungin's chemotherapeutic potential.

\section{Keywords}

Antifungal, Chemotherapeutic, Toxicity, Histopathology

\section{Introduction}

Occidiofungin is a compound purified from liquid culture of Burkholderia contaminans MS14 [1]-[8]. The *Corresponding author.

How to cite this paper: Lai Hing, S., Ravichandran, A., Escano, J., Cooley, J., Austin, F., Lu, S.-E., Pruett, S. and Smith, L. (2014) Toxicological Evaluation of Occidiofungin against Mice and Human Cancer Cell Lines. Pharmacology \& Pharmacy, 5, 10851093. http://dx.doi.org/10.4236/pp.2014.511118 
compound is a non-ribosomally synthesized cyclic peptide, composed of eight amino acids, having a base mass of $1200 \mathrm{Da}$ (Figure 1). An eighteen carbon fatty amino acid with a xylose sugar attached was identified in the compound, along with non proteinogenic amino acids 2, 4-diaminobutyric acid (DABA), and beta hydroxyl tyrosine and asparagine. Biological activity assays demonstrated its potent antifungal properties against a broad spectrum of plant and animal fungal pathogens [1] [2] [7] [8].

To date, the exact target responsible for the activity of occidiofungin is unknown. However, the strong inhibitory effect of occidiofungin on Pythium spp., which does not express ergosterol in the cell membrane and chitin in the cell wall, suggests that inhibition of ergosterol or chitin biosynthesis is not a major component of occidiofungin activity. The inhibitory activity of occidiofungin on Fusarium spp. and Cryptococcus neoformans, which are resistant to echinocandins, suggests a new antifungal mechanism may be involved [5] [7]. Pharmacodynamic experiments revealed that occidiofungin's fungicidal activity against Candida albicans is more rapid than the fungicidal activity reported for the echinocandin antifungal caspofungin [9] [10]. Potent fungicidal activity was observed against Candida albicans following a short term exposure to occidiofungin for only one hour, suggesting that occidiofungin has a strong interaction with a cellular target [1]. Furthermore, the mechanism of cell death in yeast has been determined to be apoptotic [2]. These results indicate that occidiofungin is distinctive from the four existing classes of clinically used antifungal drugs and that occidiofungin's potential as a therapeutic agent warrants further investigation. The $\mathrm{TC}_{50}$ (toxic concentration resulting in 50\% cell death) against mouse fibroblasts was $3 \mu \mathrm{M}$, which is similar to the MICs against Candida species [1]. Minimum inhibitory concentrations (MICs) of occidiofungin against Candida species are submicromolar to micromolar, which is similar in activity to echinocandins and amphotericin B [1] [9] [10]. The target for occidiofungin is presumably present in most eukaryotic cells, given that the activity of occidiofungin against mouse fibroblasts and Candida species is only a few folds different.

Before testing the efficacy of occidiofungin in an animal model or in humans, it is necessary to determine its toxicological profile. Substantial toxicity at doses expected to be required for antifungal efficacy would preclude further development of this compound as a therapeutic agent. Interestingly, a mouse toxicity study showed that doses higher than those commonly used to treat fungal infections did not result in mortality [11]. Furthermore, a dose administered intraperitoneally as high as $20 \mathrm{mg} / \mathrm{kg}$ resulted in no negative gross or microscopic findings in the liver or kidneys. Hematology and serum biochemistry tests also revealed that occidiofungin does not significantly alter organ function [11]. One possibility for the lack of observed organ specific toxicity in the previous mouse study is that occidiofungin did not absorb well into the circulatory system and that the lack of absorption was the reason for the lack of organ specific toxicity observed.

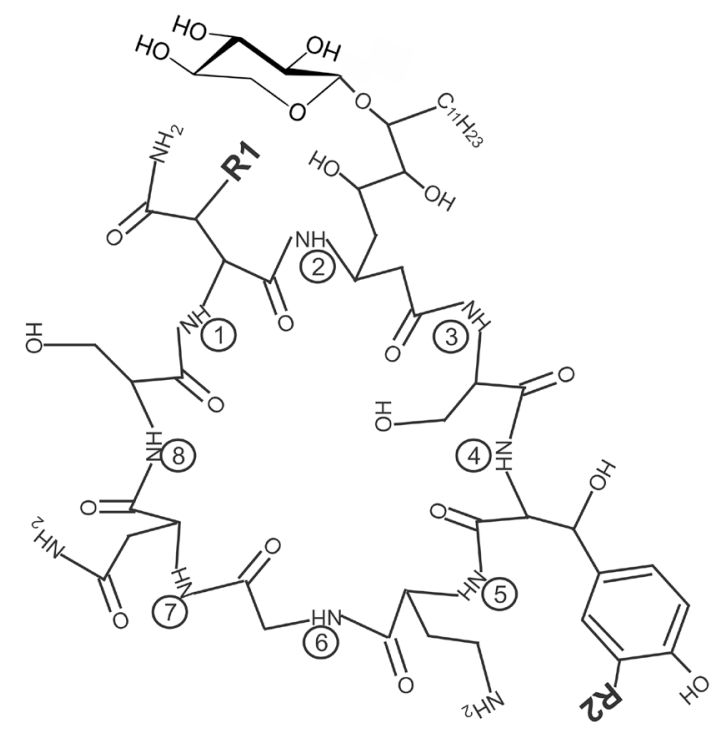

Figure 1. Covalent structure of occidiofungin. Circles represent amino acid positions: Asn/ $\beta$-hydroxy Asn1, Novel Amino Acid (NAA2), Ser3, $\beta$-hydroxy Tyr/chloro $\beta$-hydroxy Tyr4, 2,4-diaminobutyric acid (DABA)5, Gly6, Asn7, and Ser8. R1 and $\mathrm{R} 2$ represent natural variations in the covalent structure. R1 is either a proton or hydroxyl group and R2 is either a proton or chlorine. 
Considering that the target for the observed activity of occidiofungin is still unknown and that in vitro toxicity is seen in both fungal and mouse fibroblasts, the aim of this study was to evaluate the toxicity of occidiofungin in mice following intravenous administration along with its cytotoxicity against human cell lines. We found that cancer cell lines are hypersensitive to occidiofungin and that intravenous administration is well tolerated in the mouse model. Overall, our studies support the need for additional studies to evaluate occidiofungin's chemotherapeutic potential.

\section{Methods}

\subsection{Mice}

Female BALB/c mice at age of 6 - 8 weeks old were used. Female mice were used instead of male mice, given that male mice generally exhibit more aggressive behavior. These mice were purchased from Harlan and allowed to acclimate at least 2 weeks after arrival. They were housed on a 12 hour light-dark cycle in a temperature and humidity controlled animal facility that is accredited by the American Association for Accreditation of Laboratory Animal Care. Animal care and use were in accord with NIH Guidelines and Texas A\&M University regulations. Protocols used for the mice models were done in accordance to the methods reported by Luster et al. [12].

\subsection{Single Dose Toxicity Study [12]}

Occidiofungin was produced as previously described and aliquoted and lyophilized into $100 \mu$ g quantities in 1.8 $\mathrm{mL}$ centrifuge tubes. Solubility of occidiofungin in aqueous buffers is relatively low. Mice (5 mice per group) were given occidiofungin dissolved in 1.5\% hydroxy propyl-beta-cylcodextrin suspended in phosphate buffered saline (PBS). Hydroxy propyl-beta-cyclodextrin has been used extensively in pre-clinical drug testing with little or no indication of meaningful effects [13]. Spectrometric inspection at O.D.600 following addition of vehicle to the purified dried drug had negligible absorbance difference to vehicle without drug, suggesting that the drug went into solution. For the experiments, occidiofungin was administered by intravenous (i.v.) injection into the tail vein at a single dose at $5 \mathrm{mg} / \mathrm{kg}$ of body weight. The excipient control in each experiment matched the vehicle. Body weight and clinical signs (movement, posture, skin lesions, appearance of fur indicating normal grooming, and behaviors) were recorded following administration at one, four, eight, sixteen, and twenty-four hours. Necropsies were performed at 24 hours following administration of occidiofungin.

\subsection{Measurement of Toxicological Parameters [12]}

Blood and tissue samples from animals dosed at $5 \mathrm{mg} / \mathrm{kg}$ of body weight with occidiofungin in $1.5 \%$ hydroxy propyl-beta-cylcodextrin suspended in PBS were taken 24 hours following excipient or drug administration. Mice were anesthetized with isofluorane. Blood was then taken from the retroorbital plexus or heart puncture for serum biochemistry assays (alkaline phosphatase, alanine aminotransferase, aspartate aminotransferase, albumin, and blood urea nitrogen) and hematology (white blood cell count and white blood cell differentiation). Body weight was measured immediately before treatment and 24 hours later before the mice were fully anesthetized and fixed in $10 \%$ neutral buffered formalin. Histological examination was performed on a portion of each organ by using routine paraffin embedding technique and staining with hematoxylin and eosin (H \& E) [14]. All the sections were examined under light microscopy for pathological changes by a co-author of this paper, who is a board certified veterinary pathologist (J. C.).

\subsection{In Vitro Toxicity Screening}

Cancer cell lines, OVCAR8 (Center for Cancer Research (OVAR.8; Sample ID 25)), SW1088 (ATCC-HTB-12), and Toledo (ATCC CRL-2631), and normal human neonatal dermal fibroblasts (ATCC-PCS-201-010) cell line were passaged and prepped as previously described [15]-[17]. OVCAR8, SW1088, and Toledo2631 are an ovarian, brain, and B-cell lymphoma cancer cell lines, respectively. Cell counts per plate were calculated to be approximately 50,000 cells/mL. A $10 X$ stock solution of occidiofungin was prepared at $65 \mu \mathrm{M}$ concentration in $10 \%$ dimethyl sulfoxide (DMSO). Two-fold serial dilutions on a 96 well plate were set up in triplicate with starting concentration of $6.5 \mu \mathrm{M}$ and a final concentration of $3 \mathrm{nM}$. Bortezomib was used as a comparator for toxicity against human fibroblast and was serially diluted two-fold starting at a concentration of $5 \mu \mathrm{M}$ and ending at 2.5 
nM. Bortezomib is used clinically against myeloma and lymphoma cancers in patients' refractory against other chemotherapeutics [18] [19]. The plates were then incubated at $37^{\circ} \mathrm{C}$ in $5 \% \mathrm{CO}_{2}$ for 48 hours. After 48 hours, cell viability was monitored using CellTiter-Blue (Promega) cell viability assay by measuring the fluorescence emission of a redox activated dye $\left(579_{\mathrm{EX}} / 584_{\mathrm{EM}}\right)$ using a POLARstar Omega microplate reader (BMG Labtech).

\section{Statistical Analysis}

Body weight, body weight change, organ weight, serum chemistry and hematology data were analyzed by T-test or two way ANOVA followed by Bonferroni post-test using Prism GraphPad software (San Diego, CA). All the analyses were two-sided, with $\mathrm{p}<0.05$ considered statistically significant.

\section{Results}

\subsection{Anatomic and Clinical Pathology}

Results shown in Table 1 indicate the change in body weight following a single $5 \mathrm{mg} / \mathrm{kg}$ i.v. dose after 24 hours. Excipient treated mice body weight ranged between an $8 \%$ to $13 \%$ body weight gain after treatment and had a $9.6 \%$ average increase in body weight. Occidiofungin treated mice weight ranged between a $0 \%$ to a $21 \%$ body weight loss after treatment and had an average weight loss of $6.2 \%$.

A consistent behavioral response was observed at 1 hour and to a lesser extent at 4 hours post i.v. administration, in which the mice were more lethargic than excipient treated mice and had ruffled fur. They were responsive to touch, but would move slower than excipient treated mice. Treatment was not associated with more typical rodent behaviors associated with severe pain (e.g., writhing, vocalization, or lack of spontaneous locomotion). No other behavioral signs were observed. Mice behavior appeared to be normal by 8, 16, and 24 hour post injection.

Generally, no macroscopic findings were observed by histological examination. No observable differences were present in the microscopic cell morphology or macroscopic tissue morphology of esophagus, stomach, small intestine, colon, liver, pancreas, spleen, kidneys, lungs, heart and brain (Figure 2). Albumin and blood urea nitrogen (BUN) tests were similar for occidiofungin treated and excipient treated mice (Table 1). These blood tests are indicative of normal kidney and to some extent liver function. In addition, alkaline phosphatase (ALP) tests were similar between drug and excipient treated mice (Table 1). These results indicate normal liver and bone cell function. Normally aspartate amino transferase (AST) and alanine aminotransferase (ALT) tests are performed in combination with ALP to assess liver function. Elevated levels of AST and ALT do suggest heart or liver damage, but do not necessarily indicate severe organ damage. Generally a ratio of AST to ALT less than one is indicative of liver damage. The ratio in all treated mice was greater than one, suggesting that the liver is not damaged. AST values ranged from 177 to 1528 (U/l) with a mean value of 765 (U/l) and the ALT values ranged from 144 to 1273 (U/l) with a mean value of 521 (U/l) (Table 1). Given the variability in AST and ALT levels in treated mice, only the ALT levels were statistically significant.

White blood cell (WBC) counts were not statistically different between treated and untreated mice. This suggests that occidiofungin i.v. administration at $5 \mathrm{mg} / \mathrm{kg}$ had no cytotoxicological effect on blood cells or bone marrow. The absence of elevated levels further suggests normal spleen function. The percentage of neutrophils was statistically different in drug and excipient treated mice, while the percentages of lymphocytes was not statistically different (Table 1). The data does suggest an increase in the ratio of neutrophils to lymphocytes, which is indicative of an innate immune response to the drug. However, additional mice and dosing regimens will need to be done to determine if this is a genuine response. Lastly, there was no statistical difference in platelet counts between drug and excipient treated mice, suggesting that occidiofungin does not affect platelet production by the bone marrow or destroy circulating platelets.

In summary, there was no clear evidence for organ specific histological effects of occidiofungin. There were no apparent undesirable effects observed in the serum clinical chemistry and hematology parameters that would preclude additional animal testing of the compound.

\subsection{Cytotoxic Activity of Occidiofungin on Human Cell Lines}

Bortezomib is a proteosome inhibitor that has been accepted by the medical community as a potent anticancer drug. It is a potent inhibitor of multiple myeloma and pancreatic tumor growth [18] [19]. The proteasome is a 
Table 1. Percent body weight change, serum chemistry and hematology following administration of drug and excipient control.

\begin{tabular}{|c|c|c|}
\hline & \multicolumn{2}{|c|}{ Single IV Dose of Occidiofungin } \\
\hline & $5 \mathrm{mg} / \mathrm{kg}$ & $0 \mathrm{mg} / \mathrm{kg}$ \\
\hline${ }^{*}$ Weight Change \% & $-6.2 \pm 9.9$ & $+9.6 \pm 1.9$ \\
\hline \multicolumn{3}{|l|}{ Serum Biochemistry } \\
\hline Albumin (g/dl) & $3.1 \pm 0.6$ & $3.6 \pm 0.2$ \\
\hline BUN (mg/dl) & $29.6 \pm 5$ & $24.5 \pm 3.3$ \\
\hline $\operatorname{ALP}(\mathrm{U} / \mathrm{l})$ & $99 \pm 34$ & $116 \pm 17$ \\
\hline AST (SGOT) U/l & $765 \pm 692$ & $165 \pm 81$ \\
\hline "ALT (SGPT) U/l & $521 \pm 652$ & $36 \pm 10$ \\
\hline \multicolumn{3}{|l|}{ Hematology } \\
\hline WBC estimate & $4750 \pm 1225$ & $5830 \pm 1550$ \\
\hline${ }^{*}$ Neutrophils \% & $43 \pm 14$ & $16 \pm 5$ \\
\hline Lymphocytes \% & $54 \pm 15$ & $83 \pm 7$ \\
\hline Platelet estimate $(\mathrm{xK} / \mu \mathrm{l})$ & $39 \pm 21$ & $58 \pm 58$ \\
\hline
\end{tabular}

Animals were sacrificed 24 hours following i.v. administration of occidiofungin. "Signifies statistically significant differences between treated and control group. $\mathrm{p}<0.05$ was considered statistically significant.

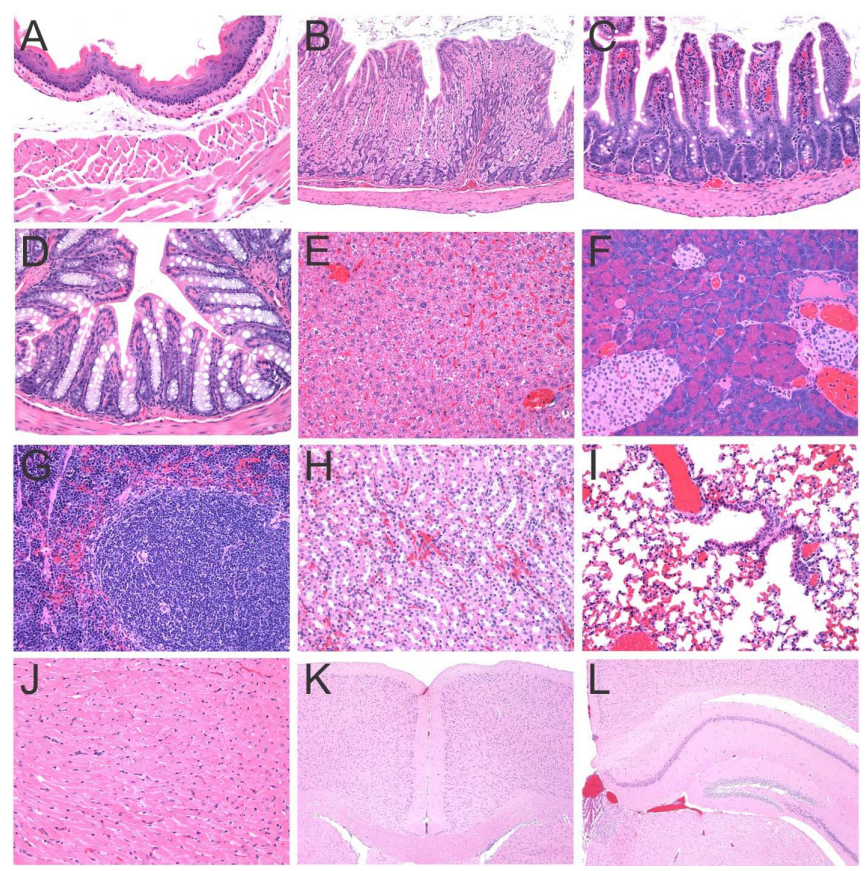

Figure 2. Representative magnifications of histological slides of mice treated with a $5 \mathrm{mg} / \mathrm{kg}$ i.v. dose. (A) Esophagus (200× magnification); (B) Stomach (200× magnification); (C) Small Intestine (200× magnification); (D) Colon (200× magnification); (E) Liver (200× magnification); (F) Pancrease (200× magnification); (G) Spleen (200× magnification); (H) Kidney (200× magnification); (I) Lung (200× magnification); (J) Heart (200× magnification); (K) Brain (100× magnification); and (L) Brain (200× magnification). Histological examination was performed on a portion of each organ by using routine paraffin embedding technique and $\mathrm{H}$ \& $\mathrm{E}$ staining. There were no histological abnormalities in the organ tissues of the treated mice in this experiment. 
multi-catalytic, multi-subunit protease complex that is responsible for the ubiquitin-dependent turnover of cellular proteins [19]-[21]. Interference with the normal function of the proteosome by bortezomib affects cellular pathways that can interfere with transcription, release of cytokines, interfere with DNA repair machinery, and the activation of signalling kinase pathways that alters a cohort of cellular responses [20]-[23]. These activities are exacerbated in multiple cancers. A typical LD50 value for bortezomib is beween 20 and $50 \mathrm{nM}$, while its toxicity is in normal cells with lower metobolism is typically in the micromolar range [20] [24]. The activity of bortezomib was compared to the activity of occidiofungin against human fibroblasts. The activity of occidiofungin was approximately eight-fold higher than that of bortezomib against the human fibroblast cell line used in this study (Figure 3). The $\mathrm{TC}_{50}$ value was $533 \mathrm{nM}$ for occidiofungin, while it was $4091 \mathrm{nM}$ for bortezomib. The $\mathrm{TC}_{50}$ values for occidiofungin against the ovarian cancer (OVAR8), astrocytoma brain cancer (SW1088), and B-cell non-hodgkin lymphoma cancer (TOLEDO CRL-2631) cell lines were $61 \mathrm{nM}, 68 \mathrm{nM}$, and $70 \mathrm{nM}$, respectively. These values are approximately eight-fold higher than that of the normal human primary dermal fibroblasts cell line tested. Furthermore, the activity against the cancer cell lines were ten to twenty-fold higher than what has been reported against Candida species. These results suggests that the biological target of occidiofungin or the cellular effect due to the interaction with the target is augmented by the cellular physiology of the human cancer cell lines.

\section{Discussion}

The antifungal activity of occidiofungin against a wide array of fungi has been tested. The antifungal activity was observed at micromolar to sub micromolar concentrations. Initial acute mouse toxicity study was conducted following subcutaneous and intraperitoneal (i.p.) administration [11]. In this study, we describe a formulation that solubilizes occidiofungin at a concentration that enabled us to evaluate occidiofungin's toxicity following an intravenous route of administration. Furthermore, we evaluated occidiofungin's toxicity against human fibroblast and cancer cells lines. Interestingly, occidiofungin was found to be a potent inhibitor of these cancer cell lines, while there was no significant toxicity observed in mice following a single i.v. dose at $5 \mathrm{mg} / \mathrm{kg}$. This concentration is about seventy-times higher than the concentration that was observed to kill the cancer cells in the in vitro toxicity assay. Our current study supports future work aimed at evaluating occidiofungin's potential for treating cancer.

The in vitro toxicity in a rat hepatoma (H4IIE) cell line was observed at $5 \mu \mathrm{M}$, with a predicted $\mathrm{TC}_{50}$ value of $3 \mu \mathrm{M}$ [11]. In this study, the in vitro toxicity against a human fibroblast cell line was observed at approximately $1 \mu \mathrm{M}$, with a predicted $\mathrm{TC}_{50}$ value around $0.5 \mu \mathrm{M}$. One key difference between these in vitro assays is the duration of drug exposure. The exposure time in this study was 48 hours, which is the typical exposure time for evaluating cancer cell lines [24], while the exposure time against the mouse hepatoma cell line in our initial in vitro toxicity assay was only 24 hours [11]. Future studies aimed at evaluated cell viability over a period of time will enable a more complete understanding of the dynamics of cell death in these assays.

In our previous mouse toxicity studies, it was clear that higher doses induced more body weight loss, and this change was dose-responsive [11]. However, body weight loss was not permanent and the mice would regain body weight when dosing ended. Lethargy and ruffled fur were observed in the single i.p. dose experiments on the first and second day after treatment [11]. The loss in body weight in conjunction with decreased thymus weight and the observed increase in neutrophil percentages suggests that occidiofungin causes a non-specific stress response. Activation of the hypothalamic-pituitary-adrenal axis by a non-specific stress response may increase circulating glucocorticoids that can cause apoptosis in developing thymocytes [25]. A loss in body weight was also observed following a $5 \mathrm{mg} / \mathrm{kg}$ i.v. administration of occidiofungin. In addition, mild lethargy and some ruffled fur were observed following the i.v. administration of occidiofungin. However, these behavioral changes were not as serious as what was observed following i.p. administration [11]. The mice were responsive and behaved normally by eight hours. There was also an increase in the percentage of neutrophils as observed in the previous study following the i.p. administration of occidiofungin. Future studies aimed at establishing the appropriate dosing regimen along with the administration of Ringers solution will need to be evaluated to determine whether the observed stress response can be alleviated. No other abnormal behavioral signs were observed. Histological examination of treated mice did not exhibit any signs of organ specific toxicity in our prior study following i.p. and subcutaneous administration [11] and the mice did not exhibit any signs of organ specific toxicity in the current study following i.v. administration. Even at a relatively high dosage of $5 \mathrm{mg} / \mathrm{kg}$, the lack 


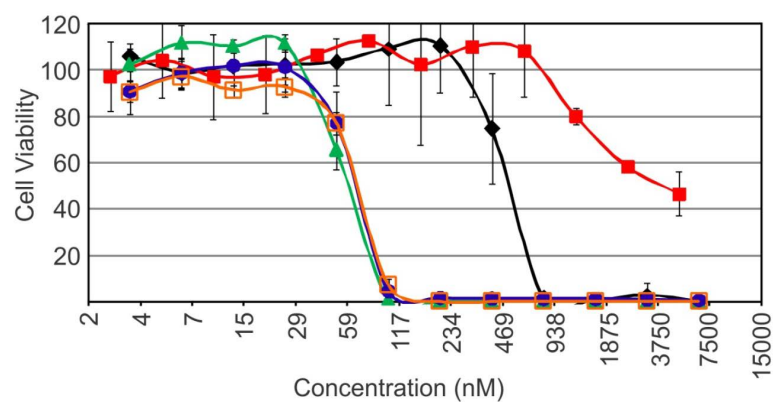

Figure 3. In vitro toxicity screen of occidiofungin. Cancer cell lines OVCAR8 (green line and triangles), SW1088 (blue line and circles), and Toledo2631 (orange lines and open squares) have an average $\mathrm{TC}_{50}$ value of $61 \mathrm{nM}, 68 \mathrm{nM}$, and $70 \mathrm{nM}$, respectively. In contrast, the average $\mathrm{TC}_{50}$ value of occidiofungin against human fibroblast (black line and filled diamonds) was $533 \mathrm{nM}$. Bortezomib had a $\mathrm{TC}_{50}$ value of $4091 \mathrm{nM}$ against the human fibroblast cell line. Results are mean of three independent experiments with one standard deviation.

of organ specific toxicity suggests that this compound may have minimal toxic effects and that the observed weight loss may be mitigated in future efficacy studies.

Viability, terminal deoxynucleotidyl transferase dUTP nick end labeling (TUNEL), reactive oxygen species (ROS) detection, membrane and cell wall stability, and membrane mimetic assays were used in a previous study to characterize the effect of occidiofungin on yeast cells [2]. Confocal and electron microscopy experiments were used to visualize morphological changes within treated cells. TUNEL and ROS detection assays revealed an increase in fluorescence with increasing concentrations of the antifungal. Yeast cells appeared to shrink in size and showed the presence of "dancing bodies" at low drug concentrations $(1 \mu \mathrm{g} / \mathrm{ml})$. Given that occidiofungin's base molecular weight is $1200 \mathrm{Da}$, this concentration is around $833 \mathrm{nM}$. A screen carried out on Saccharomyces cerevisiae gene deletion mutants in the apoptotic and autophagy pathways identified the apoptotic gene, $\Delta y c a 1$. Deletion of the yca1 gene provides a 2-fold increase in resistance. All of the autophagy mutants screened had no difference in sensitivity compared to the wild-type control [2]. Results from previous experiments demonstrate that yeast cells were dying by an apoptotic mechanism of action. The cellular target of occidiofungin is unknown, but the target is presumably present in mammalian cells given that the cancer cells were sensitive to occidiofungin in the in vitro toxicity assay. Additional studies are needed to determine whether the human cell lines die by apoptosis following exposure to occidiofungin. Furthermore, studies are warranted toward identifying occidiofungin's cellular target given its potential use as a chemotherapeutic.

In summary, occidiofungin is a natural product produced by the soil bacterium Burkholderia contaminans MS14. It was discovered by its ability to inhibit the fungal pathogen of brown patch lawn disease [3]. A soil sample taken from a tuft of green grass surrounded by dead grass has led to the discovery of its potent antifungal activity. In this study, we have found that occidiofungin also has a potent anticancer activity. Much of the recent focus on drug discovery has been spent on high throughput combinatorial chemistry approaches, which have not yielded the expected number of lead compounds for new chemotherapeutic testing [26]. Nearly half of all natural products used in the clinic have a microbial origin [26]. Our study, along with several other studies [26], demonstrates that there is still an enormous opportunity to identify novel natural products that can be further evaluated for their clinical efficacy in treating microbial infections or cancers. Additional studies in natural product discovery along with combinatorial chemistry can further expand the chances of identifying a compound that can save the lives of those in need. As research focuses oscillate, we need to be cautious of neglecting the potential of the microbial cell in drug discovery.

\section{Acknowledgements}

We would first like to thank Professor James Sacchettini and his Research Associate Kim Loesch for access to the cell lines used in this study. We would also like to acknowledge the Cancer Prevention Research Institute of Texas (CPRIT) for their support (RP 121002). 


\section{References}

[1] Ellis, D., Gosai, J., Emrick, C., Heintz, R., Romans, L., Gordon, D., Lu, S., Austin, F. and Smith, L. (2012) Occidiofungin's Chemical Stability and in Vitro Potency against Candida species. Antimicrob Agents Chemother, 56, 765769. http://dx.doi.org/10.1128/AAC.05231-11

[2] Emrick, D., Ravichandran, A., Gosai, J., Lu, S., Gordon, D.M. and Smith, L. (2013) The Antifungal Occidiofungin Triggers an Apoptotic Mechanism of Cell Death in Yeast. Journal of Natural Products, 76, 829-838. http://dx.doi.org/10.1021/np300678e

[3] Gu, G., Lu, S. and Wang, N. (2008) AmbR1 and AmbR2 Are Two Transcriptional Regulators Essential for the Antifungal Activity of Burkholderia sp Strain MS14. Phytopathology, 98, S63-S63.

[4] Gu, G., Smith, L., Liu, A. and Lu, S.-E. (2011) A genetic and Biochemical Map for the Biosynthesis of Occidiofungin, an Antifungal Produced by Burkholderia contaminans Strain MS14. Applied and Environmental Microbiology, 77, 6189-6198. http://dx.doi.org/10.1128/AEM.00377-11

[5] Gu, G., Wang, N., Chaney, N., Smith, L. and Lu, S.-E. (2009) AmbR1 is a Key Transcriptional Regulator for Production of Antifungal Activity of Burkholderia contaminans Strain MS14. FEMS Microbiology Letters, 297, 54-60. http://dx.doi.org/10.1111/j.1574-6968.2009.01653.x

[6] Gu, G. Y., Smith, L., Wang, N., Wang, H. and Lu, S.E. (2009) Biosynthesis of an Antifungal Oligopeptide in Burkholderia contaminans Strain MS14. Biochemical and Biophysical Research Communications, 380, 328-332. http://dx.doi.org/10.1016/j.bbrc.2009.01.073

[7] Lu, S.-E., Novak, J., Austin, F. W., Gu, G., Ellis, D., Kirk, M., Wilson-Stanford, S., Tonelli, M. and Smith, L. (2009) Occidiofungin, a Unique Antifungal Glycopeptide Produced by a Strain of Burkholderia contaminans. Biochemistry, 48, 8312. http://dx.doi.org/10.1021/bi900814c

[8] Ravichandran, A., Gu, G., Escano, J., Lu, S.-E. and Smith, L. (2013) The Presence of Two Cyclase Thioesterases Expands the Conformational Freedom of the Cyclic Peptide Occidiofungin. Journal of Natural Products, 76, 150-156. http://dx.doi.org/10.1021/np3005503

[9] Clancy, C.J., Huang, H., Cheng, S., Derendorf, H. and Nguyen, M.H. (2006) Characterizing the Effects of Caspofungin on Candida albicans, Candida parapsilosis and Candida glabrata Isolates by Simultaneous Time-Kill and Postantifungal-Effect Experiments. Antimicrobial Agents and Chemotherapy, 50, 2569-2572. http://dx.doi.org/10.1128/AAC.00291-06

[10] Ernst, E.J., Klepser, M.E. and Pfaller, M.A. (2000) Postantifungal Effects of Echinocandin, Azole, and Polyene Antifungal Agents against Candida albicans and Cryptococcus neoformans. Antimicrobial Agents and Chemotherapy, 44, 1108-1111. http://dx.doi.org/10.1128/AAC.44.4.1108-1111.2000

[11] Wei, T., Cooley, J., Austin, F., Lu, S., Smith, L. and Pruett, S. (2012) Nonclinical Toxicological Evaluation of Occidiofungin, a Unique Glycolipopeptide Antifungal. International Journal of Toxicology, 31, 326-336. http://dx.doi.org/10.1177/1091581812445185

[12] Luster, M.I., Portier, C., Pait, D.G., White Jr., K.L., Gennings, C., Munson, A.E. and Rosenthal, G.J. (1992) Risk Assessment in Immunotoxicology I. Sensitivity and Predictability of Immune Tests. Fundamental and Applied Toxicology: Official Journal of the Society of Toxicology, 18, 200-210. http://dx.doi.org/10.1093/toxsci/18.2.200

[13] Loftsson, T. and Brewster, M.E. (2012) Cyclodextrins as Functional Excipients: Methods to Enhance Complexation Efficiency. Journal of Pharmaceutical Sciences, 101, 3019-3032. http://dx.doi.org/10.1002/jps.23077

[14] Germolec, D.R., Kashon, M., Nyska, A., Kuper, C.F., Portier, C., Kommineni, C., Johnson, K.A. and Luster, M.I. (2004) The Accuracy of Extended Histopathology to Detect Immunotoxic Chemicals. Toxicological Sciences: An Official Journal of the Society of Toxicology, 82, 504-514. http://dx.doi.org/10.1093/toxsci/kfh271

[15] Gabay, C., Ben-Bassat, H., Schlesinger, M. and Laskov, R. (1999) Somatic Mutations and Intraclonal Variations in the Rearranged $V_{\kappa}$ Genes of B-Non-Hodgkin's Lymphoma Cell Lines. European Journal of Haematology, 63, 180-191. http://dx.doi.org/10.1111/j.1600-0609.1999.tb01766.x

[16] Hamilton, T.C., Young, R.C. and Ozols, R.F. (1984) Experimental Model Systems of Ovarian Cancer: Applications to the Design and Evaluation of New Treatment Approaches. Seminars in Oncology, 11, 285-298.

[17] Wright, W.C., Daniels, W.P. and Fogh, J. (1981) Distinction of Seventy-One Cultured Human Tumor Cell Lines by Polymorphic Enzyme Analysis. Journal of the National Cancer Institute, 66, 239-247.

[18] Roccaro, A.M., Hideshima, T., Richardson, P.G., Russo, D., Ribatti, D., Vacca, A., Dammacco, F. and Anderson, K.C. (2006) Bortezomib as an Antitumor Agent. Current Pharmaceutical Biotechnology, 7, 441-448. http://dx.doi.org/10.2174/138920106779116865

[19] Tobinai, K. (2007) Proteasome Inhibitor, Bortezomib, for Myeloma and Lymphoma. International Journal of Clinical Oncology, 12, 318-326. http://dx.doi.org/10.1007/s10147-007-0695-5 
[20] Cavo, M. (2006) Proteasome Inhibitor Bortezomib for the Treatment of Multiple Myeloma. Leukemia, 20, $1341-1352$. http://dx.doi.org/10.1038/sj.leu.2404278

[21] Chauhan, D., Hideshima, T., Mitsiades, C., Richardson, P. and Anderson, K.C. (2005) Proteasome Inhibitor Therapy in Multiple Myeloma. Molecular Cancer Therapeutics, 4, 686-692. http://dx.doi.org/10.1158/1535-7163.MCT-04-0338

[22] Anderson, K.C. (2004) Bortezomib Therapy for Myeloma. Current Hematology Reports, 3, 65-65.

[23] Anderson, K.C. (2007) Targeted Therapy of Multiple Myeloma Based upon Tumor-Microenvironmental Interactions. Experimental Hematology, 35, 155-162. http://dx.doi.org/10.1016/j.exphem.2007.01.024

[24] Adams, J., Palombella, V.J., Sausville, E.A., Johnson, J., Destree, A., Lazarus, D.D., Maas, J., Pien, C.S., Prakash, S. and Elliott, P.J. (1999) Proteasome Inhibitors: A Novel Class of Potent and Effective Antitumor Agents. Cancer Research, 59, 2615-2622.

[25] Fuchs, B.A. and Pruett, S.B. (1993) Morphine Induces Apoptosis in Murine Thymocytes in Vivo but Not in Vitro: Involvement of both Opiate and Glucocorticoid Receptors. The Journal of Pharmacology and Experimental Therapeutics, 266, 417-423.

[26] Demain, A.L. and Vaishnav, P. (2011) Natural Products for Cancer Chemotherapy. Microbial Biotechnology, 4, 687699. http://dx.doi.org/10.1111/j.1751-7915.2010.00221.x 
Scientific Research Publishing (SCIRP) is one of the largest Open Access journal publishers. It is currently publishing more than 200 open access, online, peer-reviewed journals covering a wide range of academic disciplines. SCIRP serves the worldwide academic communities and contributes to the progress and application of science with its publication.

Other selected journals from SCIRP are listed as below. Submit your manuscript to us via either submit@scirp.org or Online Submission Portal.
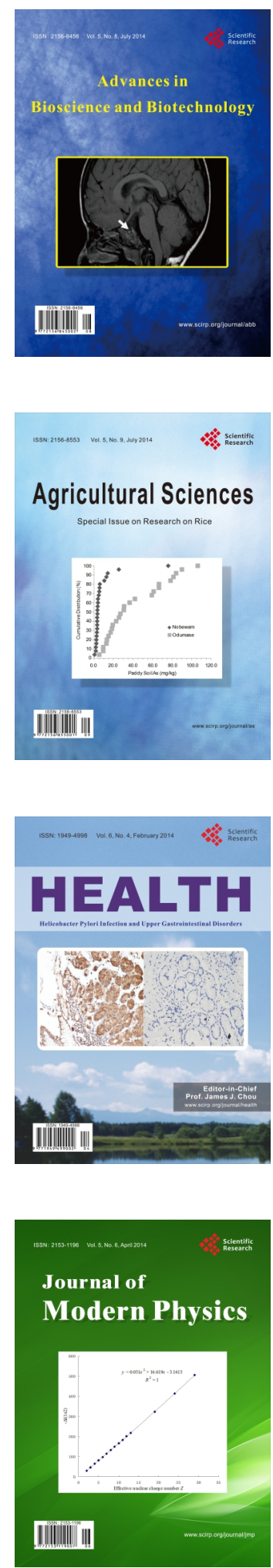
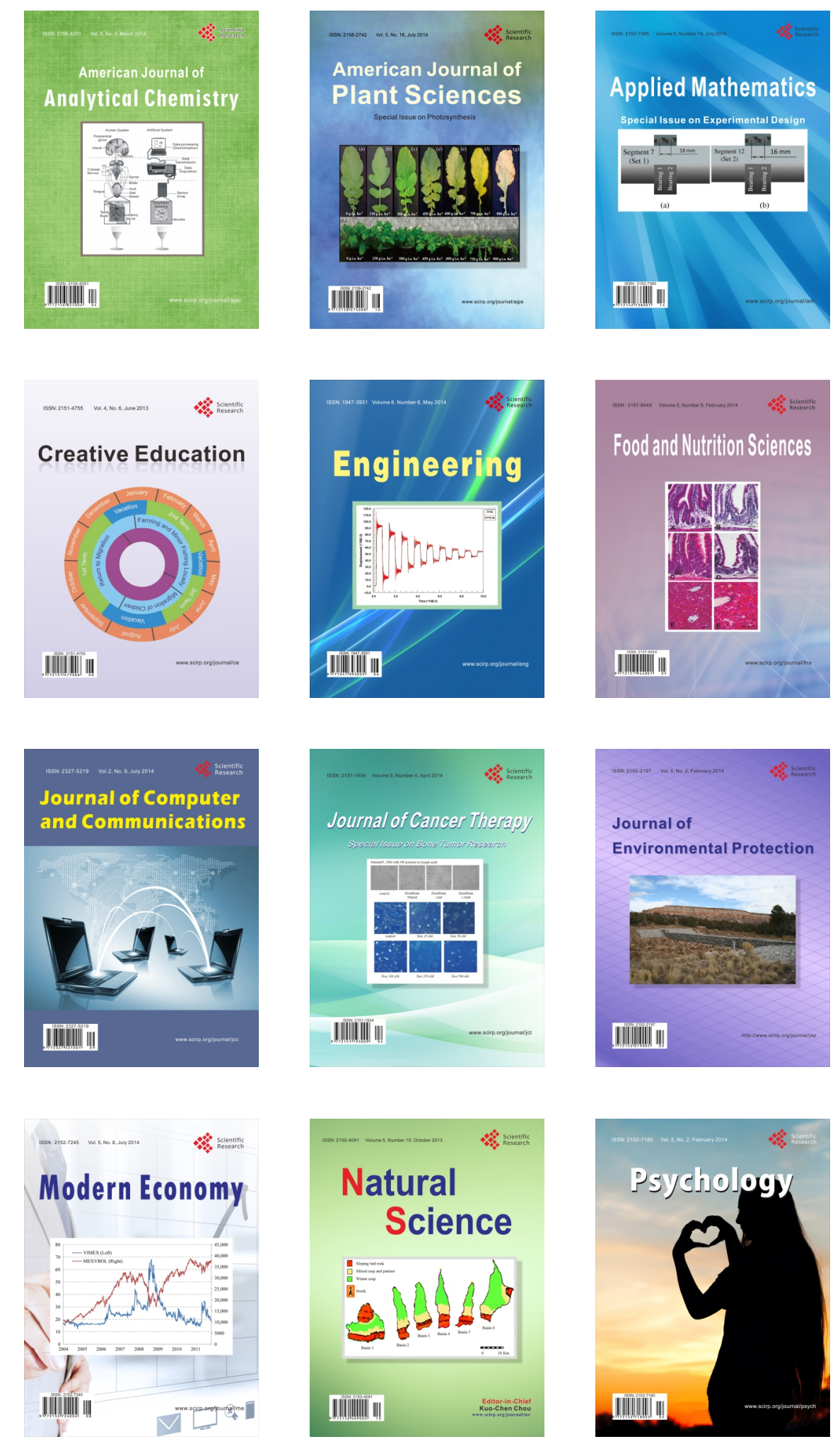